\title{
MULTIPLICAÇÃO in vitro de Bauhinia monandra Kurz (FABACEAE)
}

\author{
$\underline{\text { Jaqueline Pereira Almeida }}{ }^{1}$; Flávia Pereira de Sousa²; José Raniere Ferreira de \\ Santana $^{3}$ \\ 1.Bolsista PIBIC/CNPq, Graduanda em Ciências Biológicas, Universidade Estadual de Feira de Santana, e-mail: \\ jaquelinepereiraalmeida@gmail.com \\ 2. Doutoranda em Recursos Genéticos Vegetais, Departamento de Ciências Biológicas Universidade \\ Estadual de Feira de Santana,e-mail:flavia.sousa.ufba@gmail.com \\ 3. Orientador, Departamento de Ciências Biológicas Universidade Estadual de Feira de Santana, e-mail: e- \\ mail: raniere@uefs.br
}

Palavras -chave: cultura de tecidos; reguladores vegetais; pata-de-vaca.

\section{INTRODUÇÃO}

Bauhinia monandra Kurz (pata-de-vaca) é uma planta de hábito arbóreo ou arbustivo da família Fabaceae. Sua importância farmacêutica advêm da presença de diversos constituintes químicos, tais como esteroides, lectinas e flavonoides (ARGÔLO et al., 2004), sendo este último, o princípio ativo responsável pela atividade hipoglicemiante, já comprovada (MENEZES et al., 2007). Nesse sentido, os processos biotecnológicos que envolvem o cultivo in vitro de tecidos vegetais são de grande importância para a indústria farmacêutica, pois possibilita o aumento rápido do número de plantas, a partir de uma quantidade pequena de material vegetal (FERNANDES, 2008), uma vez que no habitat natural os metabólitos secundários produzidos pelas plantas são em pequena quantidade, sendo insuficiente para atender a demanda industrial, além disso, o cultivo in vitro possibilita o controle do ambiente físico e obtenção de mudas em espaço físico e temporal reduzidos. Desse modo, a Cultura de Tecidos Vegetais através da micropropagação, que consiste basicamente, em cultivar em ambiente asséptico com temperatura e iluminação controlados, qualquer parte da planta, em recipientes específicos contendo meio nutritivo adequado, proporciona à produção em larga escala de plantas inteiras idênticas a planta mãe (GRATTAPAGLIA; MACHADO, 1988). Apesar da importância medicinal B.monandra, não se tem relatos sobre a propagação in vitro desta espécie. Portanto, o objetivo geral deste trabalho foi estudar os efeitos dos tipos e concentrações de reguladores vegetais sobre multiplicação in vitro de $B$. monandra.

\section{METOLOGIA}

\section{Local de realização dos experimentos}

Os ensaios fisiológicos foram realizados no Laboratório de Cultura de Tecidos Vegetais, Localizado na Unidade Experimental Horto Florestal da Universidade Estadual de Feira de Santana (UEFS).

\section{Meio de cultura}

O meio de cultura utilizado em todos os experimentos foi o WPM solidificado com $0,7 \%$ de ágar e suplementado com $87,64 \mathrm{mM}$ de sacarose. Cada tratamento foi constituído de cinco repetições, sendo cada repetição composta por cinco tubos contendo um explante cada.

Experimento 1: Efeito do tipo e das concentrações de citocininas na indução de brotações em diferentes tipos de explantes de B.monandra.

Foram utilizadas plântulas de $B$. monandra com aproximadamente 30 dias de idade. A indução de brotos foi realizada em segmento nodal, internodal e foliar, os quais foram inoculados em meio de cultura com diferentes concentrações de 6-benzilaminopurina 
(BAP) ou cinetina (CIN) ou tidiazuron (TDZ) $(0,0 ; 2,0 ; 4,0 ; 6,0$ e $8,0 \mu \mathrm{M})$. O delineamento experimental foi o inteiramente casualizado em esquema fatorial $3 \times 3 \times 5$, totalizando 45 tratamentos. Após 30 dias da inoculação, foram avaliadas as seguintes variáveis: frequência de explantes responsivos, número de brotos por explante e comprimento do maior broto.

Experimento 2: Efeito da citocinina 6-benzilaminopurina (BAP) e da auxina ácido naftaleno acético (ANA) na indução de brotações em diferentes tipos de explantes de $B$. monandra.

Foram utilizadas plântulas de $B$. monandra com idade e tipos de explantes, semelhantes aos descritos no experimento 1. Os explantes foram inoculados em tubos de ensaio contendo meio de cultura suplementado com diferentes concentrações de BAP $(0,0 ; 0,5$; $1,0 ; 1,5 ; 2,0 \mu \mathrm{M})$ combinado com ANA $(0,0$ e $1,0 \mu \mathrm{M})$. O delineamento experimental foi o inteiramente casualizado em esquema fatorial $3 \times 5 \times 2$, totalizando 30 tratamentos. Após 30 dias da inoculação, foram analisadas as seguintes variáveis: frequência de explantes responsivos, número de brotos por explante, comprimento do maior broto.

\section{Analise estatística}

Os dados foram avaliados estatisticamente, mediante analise de variância, testando-se as médias pelo teste de Tukey e ajuste de equação de regressão polinomial para os fatores qualitativos e quantitativos, respectivamente. Os dados foram avaliados usando o programa SISVAR (FERREIRA, 2011).

\section{RESULTADOS E DISCUSSÃO}

Experimento 1: Efeito do tipo e das concentrações de citocininas na indução de brotações em diferentes tipos de explantes de B.monandra.

Tendo em vista que, os explantes cotiledonares e hipocótilo não apresentaram processo morfogenético, a análise estatística dos dados foi realizada apenas para as brotações originadas do segmento apical. Para a variável porcentagem de explantes responsivos, a análise de regressão indicou um modelo linear decrescente $(\mathrm{p}<0,01)$, em função das concentrações de BAP, enquanto que para respostas obtidas com o meio suplementado com CIN, observou se o modelo quadrático descendente $(\mathrm{p}<0,01)$ (Figura 1A). Por outro lado, quando o meio foi suplementado com TDZ, não se obteve um modelo matemático representativo. (Figura 1A). A maior capacidade organogênica observada (100\%) ocorreu quando o segmento apical foi inoculado em meio de cultura na ausência de regulador (Figura 1A). Com relação a variável número de brotos, a análise estatística apontou um modelo linear decrescente $(\mathrm{p}<0,05)$ para as respostas obtidas com diferentes concentrações de BAP, enquanto que para as respostas obtidas para as concentrações de CIN não se obteve um modelo matemático representativo. Já para as respostas obtidas com a suplementação do meio com TDZ, obteve-se um modelo quadrático ascendente $(\mathrm{p}<0,05)$ (Figura 1B), sendo a maior média registrada $(2,6$ brotos) na presença de $4 \mu \mathrm{M}$ de TDZ.

Em relação ao comprimento do maior broto, o modelo matemático mais representativo foi o linear decrescente e quadrático descendente $(\mathrm{p}<0,01)$ para as concentrações de BAP e CIN, respectivamente (Figura 1C).

Para o número de folhas, o modelo representativo para as respostas obtidas com o BAP e TDZ foi o quadrático descendente $(p<0,01)$ e quadrático ascendente $(p<0,01)$, respectivamente. Já para o CIN não se obteve um modelo (Figura 1D). As maiores médias registradas para os segmentos apicais $(1,6)$ foi na presença de $4 \mu \mathrm{M}$ de TDZ. 

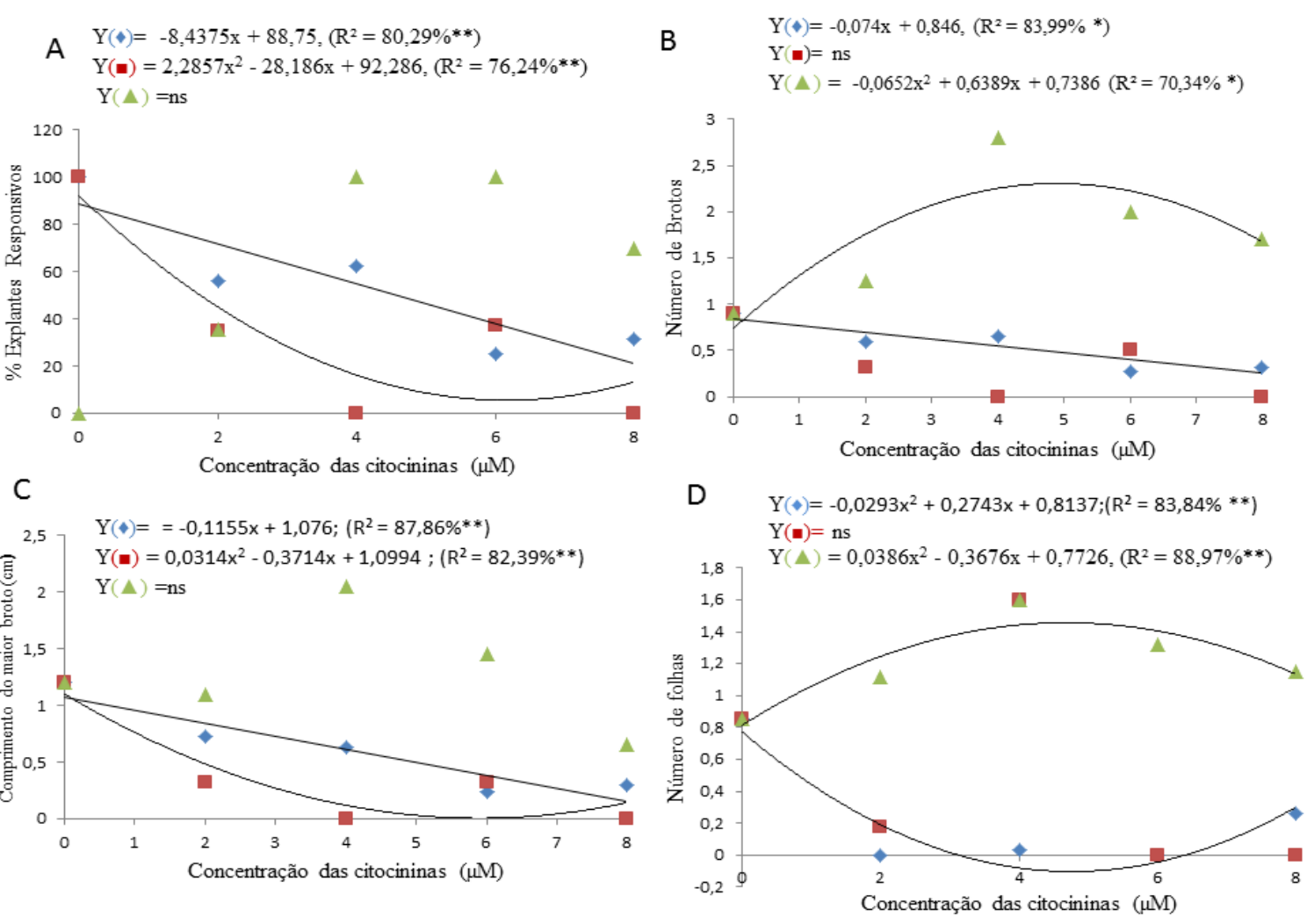

Figura 1 - Porcentagem de explantes responsivos para formação de brotos (A); Número de brotos por explante (B); Comprimento do maior broto (C) e número de folhas por explante (D) B. monandra Kurz. submetidos a diferentes concentrações de BAP, CIN e TDZ ( BAP, CIN $\backsim$ e TDZ $\triangle$ ), Feira de Santana, 2016

\section{Experimento 2: Efeito da citocinina 6-benzilaminopurina (BAP) e da auxina ácido naftaleno acético (ANA) na indução de brotações em diferentes tipos de explantes de $B$. monandra.}

Os explantes cotilédones, segmento cotiledonar e hipocótilo não apresentaram processo morfogenético, diante disso, a análise estatística dos dados foi realizada apenas para as brotações originadas do segmento apical. Para a variável número de brotos por explante, não se obteve um modelo matemático representativo para as brotações obtidas em meio suplementado com BAP na ausência de ANA e quando o meio foi suplementado com ANA a análise de regressão indicou um modelo linear decrescente ( $\mathrm{p}<0,01$ ) (Figura 2A). Isso é possível porque o efeito benéfico do BAP na multiplicação das brotações pode estar relacionado com a influência desse regulador de crescimento na divisão celular (BRUM et al. 2002). Para a variável número de número de folhas, observou-se um modelo quadrático ascendente para as concentrações de BAP acrescidas de ANA $(p \leq 0,01)$ e na sua ausência também $(\mathrm{p} \leq 0,01)$ (Figura $2 \mathrm{~B}$ ). A suplementação do meio com apenas $2,0 \mu \mathrm{M}$ de BAP promoveu uma média de aproximadamente 3,0 folhas por explante, entretanto essa média não supera as observadas quando o meio foi suplementado com a combinação de $4,0 \mu \mathrm{M}$ e $1,0 \mu \mathrm{M}$ de BAP e ANA, respectivamente. (Figura 2B). Com relação as variáveis porcentagem de explantes responsivos e comprimento do maior broto não foi obtido modelos matemáticos representativos. 

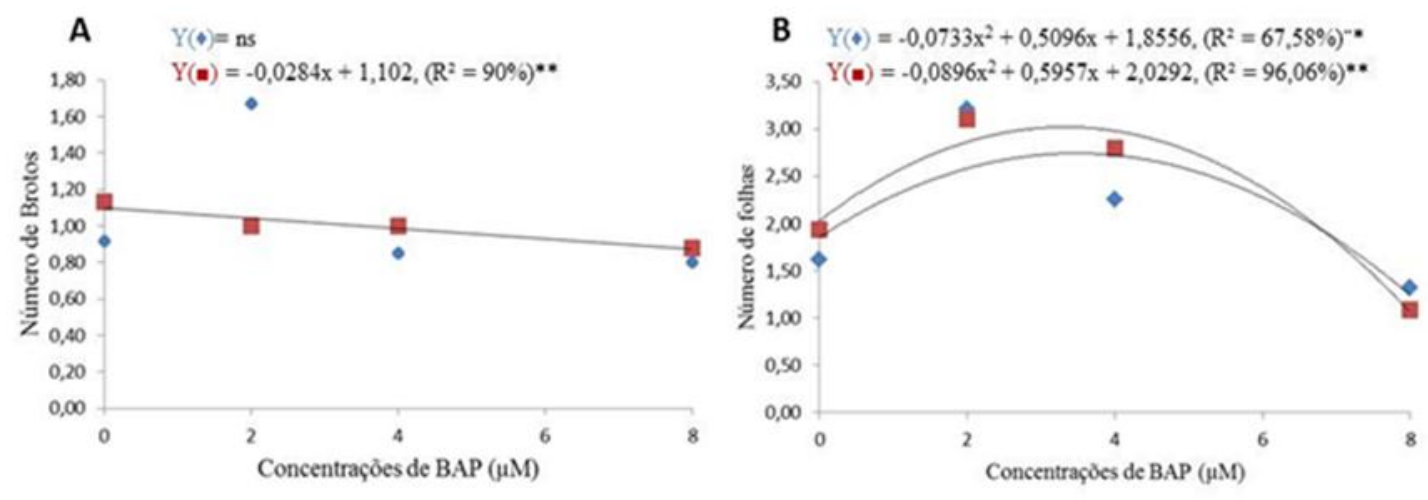

Figura 2 - Número de brotos por explante (A) e número de folhas por explante (B) B. monandra Kurz. submetidos a diferentes concentrações de BAP e ANA $(\diamond 0,0$ e $\square 1,0 \mu \mathrm{M})$. Feira de Santana, 2016.

\section{CONCLUSÃO}

A multiplicação in vitro de B. monandra é possível utilizando-se o segmento apical como fonte de explante, em meio de cultura WPM suplementado com TDZ na concentração de $4,0 \mu \mathrm{M}$.

\section{REFERÊNCIAS}

ARGÔLO, A.C; SANTA'ANA, A.E; PLETSCH, M; COELHO, L.C. Antioxidant activity of leaf extracts from Bauhinia. Bioresource Technology v.95: 229-233, 2004. BRUM, G.R. SILVA, A.B. PASQUAL, M. EFEITO DE DIFERENTES CONCENTRAÇÕES DE BAP E ANA NA PROPAGAÇÃO IN VITRO DA FIGUEIRA (Ficus carica L.). Ciênc. agrotec., Lavras. Edição Especial, p.1403-1409, dez., 2002. FERREIRA, D.F.2011.Sisvar:a computer statisticalanalysis system. Ciência e agrotecnologia. 35(6): 1039-1042.

FERNANDES, L.D.R. Aplicação de técnicas de conservação in vitro para conservação de espécies ameaçadas. Dissertação (Mestrado integrado em engenharia biológica). Faculdade de Engenharia de Recursos Naturais. Universidade do Alagarvde, Faro, 2008. GRATTAPAGLIA, D.; MACHADO, M.A. 1998. Micropropagacao. In: TORRES, A.C.; CALDAS, L.S.; BUSO, J.A. (Orgs.). Cultura de Tecidos e Transformação Genética de Plantas.

KIELSEI, P; FRANCOI, E.T.H; PARANHOSII, T.J; LIMAII, A.P.S Regeneração in vitro de Parapiptadenia rígida. Ciência Rural, Santa Maria, v.39, n.4, p.1098-1104, 2009.

MARTINS, E.R; CASTRO, D. M; CASTELLANI, D.C; DIAS, J.E. Plantas medicinais, Viçosa: UFV, Imprensa Universitária, 1995.

MENEZES, F.S; MINTO, A. B. M; KUSTER, H. S. R. R. M; SHERIDAN, H; FRANKISH. N. Hypoglycemic activity of two Brazilian Bauhinia species: Bauhinia forficata L. and Bauhinia monandra Kurz. Brazilian Journal of Pharmacognosy, Curitiba, v. 17, n. 1.p. 08-13, 2007. 